\title{
Moralitas, Peran Perangkat Desa, Dan Kepatuhan Masyarakat Dalam Membayar Pajak Bumi Dan Bangunan Pedesaan Dan Perkotaan: Sanksi Sebagai Variabel Moderating
}

\author{
Amir Hidayatulloh $^{\mathrm{a}, 1, *}$, Agung Dwi Nugroho ${ }^{\mathrm{b}, 2}$, Faishal Prahatma Ganinda ${ }^{\mathrm{b}, 3}$, Kahfi Fikrianoor ${ }^{\mathrm{b}, 4}$ \\ a,b Universitas Ahmad Dahlan \\ ${ }^{1}$ amir.hidayatulloh@act.uad.ac.id *; ${ }^{2}$ agungdwinugroho846@gmail.com; ${ }^{3}$ prahatmag@ gmail.com; \\ 4kahfifikri@gmail.com \\ * corresponding author
}

ARTICLE INFO

Keywords

Morality;

The Role of Village Official;

Tax Compliance;

Sanction;

Property Tax
ABSTRACT

This research aims to determine the factors that influence the community in paying property taxes in rural and urban areas, and to find out whether the risk variabel moderates the effect between morality and the role of village official on commuity compliance in paying property taxes in rural and urban areas. The population in this research is individual taxpayers who in bantul regency. The sample in this research is individual taxpayers who own land and buildings. The research data wase collection by distributing questionnaires to respondents who were met by researchers. Respondents in this research were 127 respondents. This research data analysis techniques uses Partial Least Square, with the help of WarpPLS. This research found that coomunity compliance in paying property taxes in rural and urban areas influenced by the role of village official and sanction. However, morality has no effect on community compliance to property taxes in rural and urban areas. This reserach also found that sanction moderate the effect of morality on the community's compliance to pay land and urban rural building taxes. However, sanction cannot moderate the effect between role of village officials on community's mandatory the effect between the role of village official on community's compliance to pay land and urban rural building taxes.

\section{PENDAHULUAN}

Tidak dapat dipungkuri lagi, penerimaan negara Indonesia terbesar berasal dari sektor pajak. Penerimaan negara dari sektor perpajakan setiap tahunnya mengalami peningkatan. Capaian penerimaan pajak sampai dengan kuartalan tahun 2017 mencapai 89,68 persen lebih besar dibandingkan persentase capaian tahun 2016 yaitu 81,60, dan tahun 2015 sebesar 81.96 persen. Pada tahun 2017, penerimaan pajak mengalami pertumbuhan sebesar 4,08 persen, pertumbuhan ini lebih rendah dibandingkan dengan tahun 2016 yang mencapai 4,25 persen. Akan tetapi, ketika unsur pengampunan pajak dan revaluasi aktiva tetap dikeluarkan dari porsi penerimaan negara, maka pada tahun 2017 penerimaan negara mengalami pertumbuhan 15,8 persen dibandingkan dengan tahun 2016 (www.pajak.go.id, 2017).

Peran pajak yang begitu besar mendorong pemerintah untuk melakukan berbagai upaya guna mencapai target yang telah ditetapkan sebelumnya. Hal ini dilakukan guna mengatasi permasalahan yang terjadi pada Direktorat Jenderal Pajak (DJP) dan pemerintah, khusunya pada permasalahan reformasi peraturan perundang-undangan dan administrasi. Selain itu, upaya lainnya yang dilakukan pemerintah dengan melakukan amandemen perundang-undangan di bidang pajak dan retribusi daerah, misalnya amandemen undang-undang pajak bumi dan bangunan yaitu Undangundang Nomor 23 Tahun 2009.

Amandemen undang-undang pajak bumi dan bangunan memungkinkan terjadi pengalihan kegiatan pendataan, penilaian, proses penetapan, kegiatan administrasi hingga pemungutan atau 
penagihan serta pelayanan PBB yang sebelumnya diselenggarakan pemerintah pusat dialihan menjadi pemerintah daerah, yang bertujuan untuk menciptakan kemudahaan dalam pelayanan pajak. Oleh karena itu, diharapkan kebijakan ini dapat meningkatkan penerimaan pajak, khususnya penerimaan pajak daerah (Undang-Undang Nomor 28, 2009).

Beberapa faktor yang memengaruhi kepatuhan masyarakat dalam membayar Pajak Bumi dan Bangunan Pedesaan dan Perkotaan (PBB P2) telah diperoleh oleh penelitian terdahulu. Faktor tersebut antara lain moralitas (Jayanto, 2011), dan peran perangkat desa (Arjani, Sulindawati, \& Wahyuni, 2017), sanksi pajak (Irmawati \& Hidayatulloh, 2019); (Karnedi \& Hidayatulloh, 2019). Perangkat desa merupakan lembaga yang paling dekat dengan masyarakat, sehingga peran perangkat desa dalam proses pembangunan sangatlah besar. Perangkat desa dapat melakukan sosialisasi mengenai pentingnya pajak, sehingga kemauan masyarakat dalam membayar pajak pun semakin meningkat. Selain langkah sosialisasi, upaya yang dapat dilakukan perangkat desa untuk meningkatkan kepatuhan yaitu dengan pemberian pembimbingan, pemahaman, serta pendekatan kepada masyarakat (Putri, 2016).

Beberapa penelitian terdahulu juga sudah menemukan bahwa sanksi dapat memoderasi hubungan pengaruh antara moralitas dan peran perangkat desa pada kepatuhan masyarakat dalam membayar pajak bumi dan bangunan pedesaan dan perkotaan, seperti (Widodo, 2010); (Arjani et al., 2017). Tingkat kepatuhan wajib pajak di Daerah Istimewa Yogyakarta khususnya Kabupaten Bantul tiap tahunnya masih rendah. Pada tahun 2018, PBB-P2 hingga menjelang batas akhir pembayaran pada bulan september baru mencapai 60 persen, bahkan masih ada desa yang capaian pembayaran pajaknya dibawah 5 persen. Banyak faktor belum maksimalnya penagihan pajak antara lain (1) pemilik lahan dan bangunan yang tidak tinggal di kabupaten Bantul, (2) peran perangkat desa yang kurang, serta (3) kurangnya kesadaran masyarakat (BPK, 2019). Dari uraian sebelumnya maka penelitian ini memiliki dua tujuan yaitu (1) untuk mengetahui faktor yang memengaruhi masyarakat dalam membayar pajak bumi dan bangunan pedesaan dan perkotaan, serta (2) untuk mengetahui apakah variabel sanski memoderating pengaruh antara moralitas dan peran perangkat desa pada kepatuhan masyarakat dalam membayar pajak bumi dan bangunan pedesaan dan perkotaan.

Menurut (Vazquez, Martinez, McKee, \& Torgler, 2005), moral pajak didefinisikan sebagai motivasi intrinsik untuk membayar pajak yang timbul dari kewajiban moral untuk membayar pajak atau kepercayaan dalam memberikan kontribusi kepada masyarakat dengan membayar pajak. Moral pajak merupakan kunci utama yang dapat menjelaskan mengapa individu berlaku jujur khususnya dalam bidang perpajakan (Cahyonowati, 2011).

Salah satu teori yang terkait dengan moral pajak adalah theory of moral reasoning, pada kontek pajak menyatakan bahwa faktor utama yang memengaruhi keputusan moral adalah perlakuan pada sanksi. Sehingga, individu yang memliliki moral reasoning rendah, penghargaan adanya keadilan pada tingkat moderat, dan issue keadilan pada tingkat yang tertinggi. Oleh karena itu, wajib pajak yang lebih menggunakan moral dalam pengambilan keputusan pembayaran pajak akan lebih patuh dibandingkan dengan wajib pajak yang lain. Sehingga, semakin tinggi moral pajak maka semakin tinggi pula kepatuhan membayar pajaknya (Jayanto, 2011). Dari uraian sebelumnya, maka hipotesis pertama $\left(\mathrm{H}_{1}\right)$ penelitian ini adalah sebagai berikut:

$\mathrm{H}_{1}$ : moralitas membayar pajak berpengaruh terhadap kepatuhan wajib pajak

Menurut (Putri, 2016), lembaga yang paling dekat dengan masyarakat adalah perangkat desa, sehingga perangkat desa memiliki peran yang sangat besar dalam proses pembangunan. Oleh karena itu, pemerintah desa diharapkan melakukan sosialisasi mengenai pentinya pajak guna meningkatkan kemauan masyarakat dalam membayar pajak. Selain itu, guna melakukan peningkatan pajak juga dapat dilakukan dengan pemberian bimbingan, pemahaman, serta pendekatan kepada masyarakat. Hal ini sesuai dengan hasil penelitian (Arjani et al., 2017) yang menyatakan bahwa peran perangkat desa berpengaruh terhadap kepatuhan masyakarat dalam membayar pajak bumi dan bangunan pedesaan dan berkotaan. Dari uraian sebelumnya, maka hoptesis kedua $\left(\mathrm{H}_{2}\right)$ penelitian ini adalah sebagai berikut:

$\mathrm{H}_{2}$ : peran perangkat desa berpengaruh terhadap kepatuhan wajib pajak 
Menurut (Resmi, 2014), sanksi pajak ada karena adanya pelanggaran pada peraturan perundang-undangan perpajakan, sehingga semakin berat sanksi ketika wajib pajak juga melakukan pelanggaran yang lebih besar. Menurut (Jatmiko, 2006), wajib pajak akan bersikap patuh untuk membayar pajak bila sanksi pajak tersebut dianggap lebih banyak merugikan. Oleh karena itu, sanksi perpajakan diduga berpengaruh terhadap kepatuhan wajib pajak. Pernyataan ini didukung oleh hasil penelitian sebelumnya (Jatmiko, 2006); (Arum, 2012); (Irmawati \& Hidayatulloh, 2019); (Karnedi \& Hidayatulloh, 2019) yang menyatakan bahwa sanksi perpajakan berpengaruh terhadap kepatuhan wajib pajak. Dari uraian sebelumnya, maka hipotesis ketiga $\left(\mathrm{H}_{3}\right)$ penelitian ini adalah sebagai berikut:

\section{$\mathrm{H}_{3}$ : sanksi pajak berpangaruh terhadap kepatuhan wajib pajak}

Moralitas pajak adalah salah satu bentuk motivasi yang muncul dari diri individu untuk membayar pajak. Moralitas pajak dibentuk melalui partisipasi warga negara, kepercayaan, sistem perpajakan, dan kebanggan. Sehingga, wajib pajak yang memiliki rasa bangga sebagai warga negara, maka wajib pajak tersebut merasa memiliki peran untuk memikirkan keadaan bangsanya (Widodo, 2010). Menurut (Arjani et al., 2017), sanksi pajak memperkuat pengaruh antara peran perangkat desa terhadap kepatuhan wajib pajak. Dari uraian sebelumnya, maka hipotesis keempat $\left(\mathrm{H}_{4}\right)$ penelitian ini adalah sebagai berikut.

\section{$\mathrm{H}_{4}$ : sanksi pajak memoderasi pengaruh moralitas terhadap kepatuhan wajib pajak}

Perangkat desa telah melakukan berbagai upaya dalam pemungutan pajak bumi dan bangunan pedesaan perkotaan, antara lain memberikan stimulus kepada seluruh elemen masyarakat bahwa pembayaran pajak merupakan kewajiban warga negara. Namun, beberapa masyarakat tidak berkeinginan untuk membayar pajak. Sehingga, perangkat desa juga menyiapkan strategi yaitu perangkat desa akan melakukan penarikan pajak ketika masyarakat sudah mendapatkan hasil dari pekerjaanya (Putri, 2016). Menurut (Arjani et al., 2017), sanksi pajak memoderasi pengaruh perangkat desa terhadap kepatuhan wajib pajak. Dari uraian sebelumnya, maka hipotesis kelima $\left(\mathrm{H}_{5}\right)$ penelitian ini adalah sebagai berikut:

$\mathrm{H}_{5}$ : sanksi pajak memoderasi pengaruh peran perangkat desa terhadap kepatuhan wajib pajak

\section{METODE PENELITIAN}

Populasi dalam penelitian ini wajib pajak orang pribadi yang berdomisili di Kabupaten Bantul. Sampel dalam penelitian ini adalah wajib pajak orang pribadi yang memiliki tanah dan bangunan. Teknik pengambilan sampel dalam penelitian ini menggunakan convenience sampling. Data dalam penelitian ini dikumpulkan dengan menyebarkan kepada responden. Variabel dalam penelitian ini meliputi kepatuhan pajak, moralitas, peran perangkat desa, dan serta sanksi pajak. Definisi operasional dan pengukuran variabel disajikan pada tabel 1. Teknik analisis data dalam penelitian ini menggunakan Partial Least Square (PLS), dengan batuan alat WarpPLS.

Tabel 1. Definisi Operasional dan Pengukuran Variabel

\begin{tabular}{|c|c|c|c|c|}
\hline Variabel & Definisi & Sumber & Pengukuran & Definisi \\
\hline Kepatuhan Pajak & 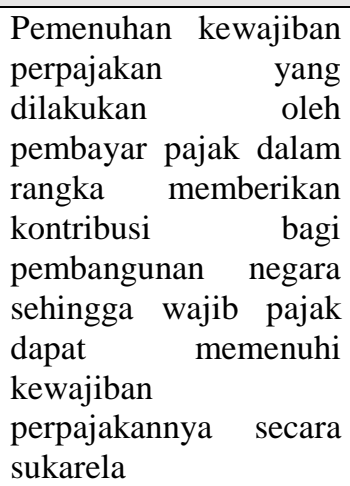 & (Tiraada, 2013) & $\begin{array}{l}\text { Empat item } \\
\text { pertanyaan dengan } \\
\text { menggunakan } \\
\text { skala likert lima } \\
\text { poin }\end{array}$ & $\begin{array}{l}\text { (Irmawati \& } \\
\text { Hidayatulloh, } \\
\text { 2019) }\end{array}$ \\
\hline Moralitas & $\begin{array}{l}\text { Motivasi intrinsik } \\
\text { untuk mematuhi dan }\end{array}$ & $\begin{array}{l}\text { (Torgler \& } \\
\text { Schneider, 2006) }\end{array}$ & $\begin{array}{lr}\text { Empat } & \text { item } \\
\text { pertanyaan dengan }\end{array}$ & $\begin{array}{l}\text { (Arjani et al., } \\
2017)\end{array}$ \\
\hline
\end{tabular}




\begin{tabular}{|l|l|l|l|l|}
\hline & $\begin{array}{l}\text { membayar pajak } \\
\text { sehingga berkontribusi } \\
\text { secara sukarela }\end{array}$ & & $\begin{array}{l}\text { menggunakan } \\
\text { skala likert lima } \\
\text { poin }\end{array}$ & \\
\hline $\begin{array}{l}\text { Peran Perangkat } \\
\text { Desa }\end{array}$ & $\begin{array}{l}\text { Kegiatan memengaruhi } \\
\text { masyarakat }\end{array}$ & $\begin{array}{l}\text { (Thoha, 1995) } \\
\text { dalam (Fachrizal, } \\
2013)\end{array}$ & $\begin{array}{l}\text { Empat pertanyaan } \\
\text { dengan } \\
\text { menggunakan } \\
\text { skala likert lima } \\
\text { poin }\end{array}$ & $\begin{array}{l}\text { (Arjani et al., } \\
2017)\end{array}$ \\
\hline Sanksi Pajak & $\begin{array}{l}\text { Jaminan bahwa } \\
\text { ketentuan peraturan } \\
\text { perundang-undangan } \\
\text { perpajakan akan } \\
\text { dituruti/ditati/dipatuhi. }\end{array}$ & $\begin{array}{l}\text { Empat pertanyaan } \\
\text { dengan } \\
\text { menggunakan } \\
\text { skala likert lima } \\
\text { poin }\end{array}$ & $\begin{array}{l}\text { Hidayatulloh, } \\
\text { 2019) }\end{array}$ \\
\hline
\end{tabular}

\section{HASIL DAN PEMBAHASAN}

Responden dalam penelitian ini berjumlah 127 responden, dan didominasi oleh responden berjenis kelamin laki-laki (77) responden. Sedangkan, 50 responden berjenis kelamin perempuan. Usia responden didominasi oleh 46-50 tahun (44 responden). Sedangkan, tingkat pendidikan respoden didominasi oleh tingkat pendidikan SMA/SMK (71 responden). Deskriptif mengenai usia responden dan tingkat pendidikan disajikan pada tabel 2.

Tabel 2. Deskripsi Usia dan Tingkat Pendidikan

\begin{tabular}{|l|l|}
\hline Keterangan & Frekuensi \\
\hline Usia Responden & 14 \\
\hline 35-40 Tahun & 39 \\
\hline 41-45 Tahun & 44 \\
\hline 56-50 Tahun & 23 \\
\hline 51-55 Tahun & 7 \\
\hline 56-60 Tahun & \multicolumn{2}{|l|}{} \\
\hline Pendidikan & 5 \\
\hline SD & 34 \\
\hline SMP & 71 \\
\hline SMA/SMK & 16 \\
\hline S1 & 1 \\
\hline S2/S3 &
\end{tabular}

Sumber: data primer, diolah (2019)

Pengujian hipotesis dalam penelitian menggunakan PLS dengan bantuan WarpPLS. Pada analisis PLS terdiri dari dua sub model yaitu model pengukuran (outer model) dan model struktural (inner model). Model pengukuran digunakan untuk uji validitas dan uji reliabilitas. Sedangkan, model struktural digunakan untuk pengujian hipotesis serta mengevaluasi model struktural dengan menggunakan $\mathrm{R}^{2}$. Hasil model pengukuran disajikan pada tabel 3 dan tabel 4.

Tabel 3. Uji Validitas

\begin{tabular}{|c|c|c|c|c|c|}
\hline & Moralitas & Peran Perangkat Desa & Sanksi Pajak & Kepatuhan Wajib Pajak & AVE \\
\hline M1 & $(0,701)$ & & & & \multirow[t]{4}{*}{$(0,757)$} \\
\hline M2 & $(0,732)$ & & & & \\
\hline M3 & $(0,652)$ & & & & \\
\hline M4 & $(0,632)$ & & & & \\
\hline PD1 & & $(0,733)$ & & & \multirow[t]{4}{*}{$(0,774)$} \\
\hline PD2 & & $(0,665)$ & & & \\
\hline PD3 & & $(0,699)$ & & & \\
\hline PD4 & & $(0,726)$ & & & \\
\hline S1 & & & $(0,772)$ & & \multirow[t]{4}{*}{$(0,784)$} \\
\hline S2 & & & $(0,807)$ & & \\
\hline S3 & & & $(0,677)$ & & \\
\hline S4 & & & $(0,603)$ & & \\
\hline KP1 & & & & $(0,805)$ & \multirow[t]{4}{*}{$(0,803)$} \\
\hline KP2 & & & & $(0,833)$ & \\
\hline KP3 & & & & $(0,731)$ & \\
\hline KP4 & & & & $(0,612)$ & \\
\hline
\end{tabular}

Sumber: data primer, diolah (2019) 
Tabel 4. Uji Reliabilitas

\begin{tabular}{|c|c|c|c|c|}
\hline & Moralitas & $\begin{array}{c}\text { Peran Perangkat } \\
\text { Desa }\end{array}$ & Sanski Pajak & $\begin{array}{c}\text { Kepatuhan Wajib } \\
\text { Pajak }\end{array}$ \\
\hline Composie Reliabilty & 0,867 & 0,879 & 0,885 & 0,898 \\
\hline
\end{tabular}

Sumber: data primer, diolah (2019)

Tabel 2 menunjukan bahwa penelitian ini memenuhi uji validitas. Hal ini ditunjukan dengan nilai Average Variance Extracted (AVE) diatas 0,5 dan nilai loading diatas 0,5 (Imam \& Latan, 2014). Tabel 3 menunjukan nilai composite reliability masing-masing variabel memiliki nilai ditas 0,7. Sehingga, penelitian ini memenuhi uji reliabilitas. Tahap selanjutnya setelah pengujian inner model, penelitian ini melakukan pengujian outer model. Hasil outer model disajikan pada gambar 1 .

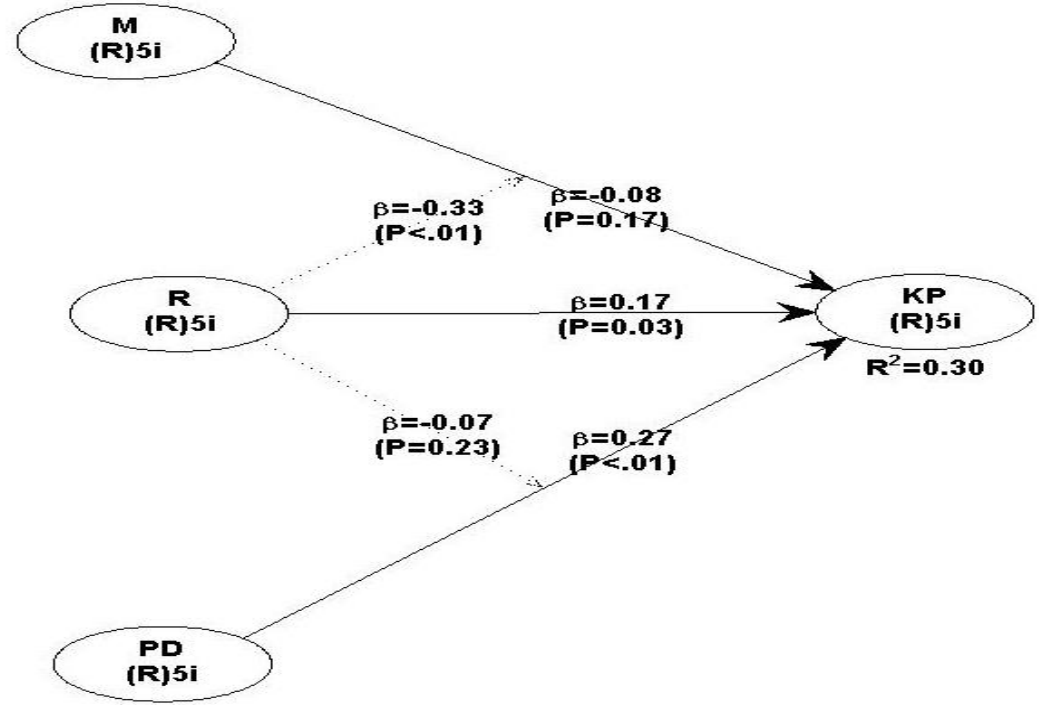

Gambar 1. Hasil Uji Outer Model

Sumber: data primer, diolah (2019)

Keterangan:

M : Moralitas

PD : Peran Perangkat Desa

$\mathrm{R} \quad$ : Sanksi Pajak

KP : Kepatuhan Pajak

Gambar 1 menunjukan bahwa variabel kepatuhan wajib pajak dapat dijelaskan oleh variabel moralitas dan peran perangkat desa sebesar 30 persen, sedangkan 70 persen variabel kepatuhan wajib pajak dijelaskan oleh variabel lain di luar model. Gambar 2 juga menunjukan bahwa kepatuhan wajib pajak dalam membayar pajak bumi dan bangunan pedesaan dan perkotaan dipengaruhi oleh faktor sanksi pajak dan peran perangkat desa. Hal ini ditunjukan dengan nilai signifikasi sanksi pajak $(0,03)$ dan peran perangkat desa $(<0,01)$ yang lebih kecil dibandingkan dengan 0,05 . Atau dengan kata lain, hipotesis kedua $\left(\mathrm{H}_{2}\right)$ dan hipotesis ketiga $\left(\mathrm{H}_{3}\right)$ penelitian ini terdukung. Hal ini berarti pemerintah desa diharapkan dapat melakukan sosialisasi mengenai pentingnya pajak kepada masyarakat. Selain itu, pemerintah juga diupayakan dapat memberikan bimbingan, pemahaman, serta pendekatan kepada masyarakat. Hal ini karena peran perangkat desa dapat memengaruhi kepatuhan masyarakat untuk membayar pajak bumi dan bangunan pedesaan dan perkotaan. Hasil ini mendukung hasil penelitian sebelumnya (Arjani et al., 2017), salah satu faktor yang memengaruhi kepatuhan wajib pajak adalah peran perangkat desa.

Faktor lain yang memengaruhi kepatuhan wajib pajak adalah adanya sanksi perpajakan. Sehingga, wajib pajak akan bersikap patuh untuk membayar pajak apabila wajib pajak tersebut menganggap bahwa sanksi tersebut merugikan bagi dirinya. Hal ini didukung oleh hasil penelitian sebelumnya (Jatmiko, 2006); (Arum, 2012); (Irmawati \& Hidayatulloh, 2019); (Karnedi \& Hidayatulloh, 2019) yang menyatakan bahwa sanksi perpajakan berpengaruh terhadap kepatuhan wajib pajak. 
Kepatuhan pajak tidak dipengaruhi oleh moralitas. Atau dengan kata lain, hipotesis pertama $\left(\mathrm{H}_{1}\right)$ penelitian ini tidak terdukung. Hal ini ditunjukan dengan nilai signifikasi $(0,17)$ yang lebih besar dibandingkan 0,05 . Hal ini berarti bahwa moralitas tidak akan memengaruhi kepatuhan wajib pajak karena menurut teori atribusi eksternal, perilaku wajib pajak dapat dipengaruhi oleh faktor eskternal seperti lingkungan keluarga, lingkungan masyarakat. Pernyataan ini didukung oleh hasil penelitian (Khaerunnisa \& Wiratno, 2014) yang menyatakan bahwa moralitas tidak berpengaruh terhadap kepatuhan wajib pajak. Begitu juga, hasil penelitian (Hidayatulloh, 2016) menyatakan bahwa norma subjektif (lingkungan keluarga, rekan kerja) berpengaruh terhadap niat untuk menggelapkan pajak.

Penelitian ini juga memperoleh hasil bahwa sanksi pajak memoderasi pengaruh antara moralitas. Atau dengan kata lain, hipotesis keempat $\left(\mathrm{H}_{4}\right)$ penelitian ini terdukung. Hasil penelitian ini mendukung hasil penelitian sebelumnya (Arjani et al., 2017), sanksi pajak memperkuat moralitas kepatuhan pajak. Sedangkan, sanksi pajak tidak dapat memoderasi pengaruh antara peran perangkat desa terhadap kepatuhan pajak. Hal ini karena perangkat desa melakukan penarikan pajak ketika masyarakat sudah mendapatkan hasil dari pekerjaan (Putri, 2016). Menurut (Arjani et al., 2017). Begitu juga, hasil penelitian (Jatmiko, 2006); (Arum, 2012); (Irmawati \& Hidayatulloh, 2019); (Karnedi \& Hidayatulloh, 2019) yang menemukan hasil bahwa sanksi perpajakan memengaruhi kepatuhan wajib pajak secara langsung. Sehingga, ketika wajib pajak merasa sanksi tersebut akan merugikan bagi dirinya, maka wajib tersebut akan berupaya untuk menghindari perbuatan yang dapat menimbulkan sanksi.

\section{KESIMPULAN}

Kepatuhan masyarakat untuk membayar pajak bumi dan bangunan pedesaan dan perkotaan dipengaruhi oleh peran perangkat desa dan sanksi pajak. Hal ini berarti perangkat desa memiliki peran dalam meningkatkan kepatuhan masyarakat untuk membayar pajak bumi dan bangunan pedesaan dan perkotaan. Langkah yang dapat dilakukan oleh pemerintah desa adalah dengan melakukan sosialisasi, memberikan bimbingan, pemahaman serta melakukan pendekatan kepada masyarakat. Begitu juga, ketika masyarakat menganggap bahwa sanksi yang akan diterima berat ketika melanggar aturan perpajakan, maka wajib pajak tersebut akan bersikap lebih patuh. Selain itu, keberadaan sanksi pajak juga akan memoderasi pengaruh moralitas terhadap kepatuhan masyarakat untuk membayarkan pajak bumi dan bangungan pedesan dan perkotaan.

Penelitian ini memiliki keterbatasan yaitu nilai $\mathrm{R}^{2}$ penelitian ini sebesar 30 persen yang mengindikasi bahwa 70 persen variabel kepatuhan dapat dijelaskan oleh variabel lain di luar model. Oleh karena itu, penelitian selanjutnya dapat menambah variabel independen seperti norma sosial, religiusitas, dan lain sebagainya.

\section{DAFTAR PUSTAKA}

[1]. Arjani, N. N. S., Sulindawati, N. L. G. E., \& Wahyuni, M. A. (2017). Pengaruh Motivasi, Moralitas, dan Peran Perangkat Desa Terhadap Kepatuhan Masyarakat Dalam Membayar Pajak Bumi dan Bangunan Perdesaan dan Perkotaan Dengan Sanksi Perpajakan Sebagai Variabel Moderasi. Jurnal Ilmiah Mahasiswa Akuntansi UNDIKSHA, 7(1).

[2]. Arum, H. P. (2012). Pengaruh Kesadaran Wajib Pajak, Pelayanan Fiskus, dan Sanksi Pajak Terhadap Kepatuhan Wajib Pajak Orang Pribadi Yang Melakukan Kegiatan Usaha dan Pekerjaan Bebas (Studi di Wilayah KPP Pratama Cilacap) (Universitas Diponegoro Semarang). Retrieved from http://eprint.undip.ac.id/35890/1/SKRIPSI_ARUM.pdf

[3]. BPK. (2019). Tagihan PBB-P2 Jadi Temuan BPK. Retrieved from https://yogyakarta.bpk.go.id/tagihan-pbb-p2-jadi-temuan-bpk/

[4]. Cahyonowati. (2011). Model Moral dan Kepatuhan Perpajakan Wajib Pajak Orang Pribadi. Jurnal Akuntansi Dan Auditing Indonesia, 15(11), 161-177.

[5]. Fachrizal, M. (2013). Kepemimpinan Lurah dalam Meningkatkan Kinerja Pegawai. Jurnal Pemerintahan Integratif, 1.

[6]. Hidayatulloh, A. (2016). Faktor-faktor yang mendorong wajib pajak pribadi untuk menggelapkan pajak. Optimum: Jurnal Ekonomi Dan Pembangunan, 6(2), 189-200. 
[7]. Imam, G., \& Latan, H. (2014). Partial Least Square (PLS) konsep teknik dan aplikasi. Semarang: Universitas Diponegoro Semarang.

[8]. Irmawati, J., \& Hidayatulloh, A. (2019). Determinan Kepatuhan Wajib Pajak UMKM di Kota Yogyakarta. Jurnal Sistem Informasi, Keuangan, Auditing Dan Perpajakan, 3(2), 112-121.

[9]. Jatmiko, A. N. (2006). Pengaruh Sikap Wajib Pajak Pada Pelaksanaan Sanksi Denda, Pelayanan Fiskus, dan Kesadaran Perpajakan Terhadap Kepatuhan Wajib Pajak (Universitas Diponogoro). Retrieved from http://eprints.undip.ac.id/15261/1/Agus_Nugroho_Jatmiko.pdf. 02November 2017

[10]. Jayanto, P. Y. (2011). Faktor-Faktor Ketidapatuhan Wajib Pajak. JDM, 2(1).

[11]. Karnedi, N. F., \& Hidayatulloh, A. (2019). Pengaruh Kesadaran Perpajakan, Sanksi Pajak dan Tax Amnesty Terhadap Kepatuhan Wajib Pajak Orang Pribadi. 12(1), 1-9. https://doi.org/10.22441/profita.2019.v12.01.001

[12]. Khaerunnisa, I., \& Wiratno, A. (2014). Pengaruh Moralitas Pajak, Budaya Pajak, Dan Good Governance Terhadap Kepatuhan. Jurnal Riset Akuntansi Dan Perpajakan, 1(2), 211-224.

[13]. Mardiasmo. (2016). Perpajakan (2016th ed.). CV Andi.

[14]. Putri, R. L. (2016). Pengaruh Motivasi Membayar Pajak dan Tingkat Pendidikan Terhadap Kepatuhan Wajib Pajak Orang Pribadi. Universitas Negeri Yogyakarta.

[15]. Resmi, S. (2014). Perpajakan: Teori dan kasus. Jakarta: Salemba Empat.

[16]. Tiraada, T. A. (2013). Kesadaran Perpajakan, Sanksi Pajak, Sikap Fiskus Terhadap Kepatuhan WPOP di Kabupaten Minahasa Selatan. Jurnal EMBA, 1(3).

[17]. Torgler, B., \& Schneider, F. (2006). What Shapes Attitudes Toward Paying Tax? Evidence from Multicultural European Countries. Social Science Quarterly, 88(2), 443-465.

[18]. Undang-Undang Nomor 28 Tahun 2009 Tentang Pajak Daerah dan Retribusi Daerah

[19]. Vazquez, R. G. C., Martinez, J., McKee, M., \& Torgler, B. (2005). Effects of Tax Morale on Tax Compliance and Survey Evidence. Departement of Economics University of Tennessee, $29,1-36$.

[20]. Widodo, W. (2010). Moralitas, Budaya dan Kepatuhan Pajak. Jakarta: CV Alfabeta.

[21]. Www.pajak.go.id. (2017). Laporan Kinerja Tahun 2017. Retrieved from https://www.pajak.go.id/id/laporan-kinerja-tahun-2017 